\title{
Feasibility of Using a Smartwatch to Intensively Monitor Patients With Chronic Obstructive Pulmonary Disease: Prospective Cohort Study
}

Robert Wu ${ }^{1,2}$, MSc, MD; Daniyal Liaqat ${ }^{3}$, BSc; Eyal de Lara ${ }^{3}$, PhD; Tatiana Son ${ }^{4}, \mathrm{MA} ;$ Frank Rudzicz ${ }^{3,4}, \mathrm{PhD}$; Hisham Alshaer $^{4}$, MD, PhD; Pegah Abed-Esfahani ${ }^{3}$, BSc; Andrea S Gershon ${ }^{2,5,6}$, MSc, MD

${ }^{1}$ Division of General Internal Medicine, University Health Network, Toronto, ON, Canada

${ }^{2}$ Department of Medicine, University of Toronto, Toronto, ON, Canada

${ }^{3}$ Department of Computer Science, University of Toronto, Toronto, ON, Canada

${ }^{4}$ Toronto Rehabilitation Institute, University Health Network, Toronto, ON, Canada

${ }^{5}$ Sunnybrook Research Institute, Sunnybrook Health Sciences Centre, Toronto, ON, Canada

${ }^{6}$ Institute for Clinical Evaluative Sciences, Toronto, ON, Canada

\section{Corresponding Author:}

Robert Wu, MSc, MD

Division of General Internal Medicine

University Health Network

$14 \mathrm{EN}-222$

200 Elizabeth Street

Toronto, ON,

Canada

Phone: 14163404567

Email: robert.wu@uhn.ca

\section{Abstract}

Background: Acute exacerbations of chronic obstructive pulmonary disease (COPD) are associated with accelerated decline in lung function, diminished quality of life, and higher mortality. Proactively monitoring patients for early signs of an exacerbation and treating them early could prevent these outcomes. The emergence of affordable wearable technology allows for nearly continuous monitoring of heart rate and physical activity as well as recording of audio which can detect features such as coughing. These signals may be able to be used with predictive analytics to detect early exacerbations. Prior to full development, however, it is important to determine the feasibility of using wearable devices such as smartwatches to intensively monitor patients with COPD.

Objective: We conducted a feasibility study to determine if patients with COPD would wear and maintain a smartwatch consistently and whether they would reliably collect and transmit sensor data.

Methods: Patients with COPD were recruited from 3 hospitals and were provided with a smartwatch that recorded audio, heart rate, and accelerations. They were asked to wear and charge it daily for 90 days. They were also asked to complete a daily symptom diary. At the end of the study period, participants were asked what would motivate them to regularly use a wearable for monitoring of their COPD.

Results: Of 28 patients enrolled, 16 participants completed the full 90 days. The average age of participants was 68.5 years, and 36\% (10/28) were women. Survey, heart rate, and activity data were available for an average of 64.5, 65.1, and 60.2 days respectively. Technical issues caused heart rate and activity data to be unavailable for approximately 13 and 17 days, respectively. Feedback provided by participants indicated that they wanted to actively engage with the smartwatch and receive feedback about their activity, heart rate, and how to better manage their COPD.

Conclusions: Some patients with COPD will wear and maintain smartwatches that passively monitor audio, heart rate, and physical activity, and wearables were able to reliably capture near-continuous patient data. Further work is necessary to increase acceptability and improve the patient experience.

(JMIR Mhealth Uhealth 2018;6(6):e10046) doi: $\underline{10.2196 / 10046}$ 


\section{KEYWORDS}

chronic obstructive pulmonary disease; monitoring; physiologic disease management; wearable; telehealth

\section{Introduction}

Chronic obstructive pulmonary disease (COPD) affects 251 million people worldwide. In 2015 , it was estimated to have caused 3.17 million deaths, $5 \%$ of all deaths globally [1]. People with COPD have exacerbations or episodes when their breathing, cough, or sputum production worsens, and treatment is warranted. Such acute exacerbations of COPD (AECOPDs) accelerate the decline in lung function, diminish quality of life, and lead to death [2-8]. Early treatment can reduce the severity of AECOPD and prevent hospitalizations, reduce morbidity, and likely reduce mortality $[4,9]$.

Early treatment of AECOPD can be provided with early detection. Patients may be able to detect exacerbations earlier with information from frequent or continuous monitoring of physiologic parameters such as heart rate, respiratory rate, coughing, oxygen saturation, and physical activity. A recent systematic review examined the effectiveness of home telemonitoring for predicting an AECOPD [10]. Of the 16 studies that evaluated the predictive ability of systems that recorded physiologic parameters or symptoms, none appeared to be clinically reliable in predicting AECOPDs. One reason may be that most data are collected too infrequently. Most systems collected data once daily, potentially missing the sensitivity required to detect early AECOPDs [10].

The emergence of consumer wearables such as smartwatches offers a potential practical and affordable method to monitor and collect early signs frequently, even continuously, to detect concerning symptoms. However, such devices can only work if they are worn and maintained. While elderly patients have said they would be willing to use telemonitoring devices to improve their care [11], studies have found recruitment difficulties, with up to $80 \%$ refusing to use the device and low patient adherence $[12,13]$. The difficulty in reliably measuring physiologic data has been another reason attributed to the inability of telemonitoring to predict AECOPDs [10].

Our overall goal is to improve the care of people with COPD and reduce hospitalizations by providing patients with a practical way to monitor their condition to detect early exacerbations, allowing for timely intervention. In this study, we sought to determine whether patients with COPD would use, wear, and maintain a smartwatch for extended periods of time and whether such a device could reliably capture near-continuous sensor data.

\section{Methods}

\section{Patient Recruitment}

Participants with COPD aged 40 years and older were recruited from 3 hospitals - Sunnybrook Health Sciences Centre, Toronto General Hospital, and Toronto Western Hospital—and from 3 sources: hospital inpatient wards, respirology clinics, and responses to posters soliciting people with COPD. We excluded those who could not speak English, those who resided in a long-term care facility, those who had a medical condition that impaired their ability to participate in the study, and those who did not provide informed consent. Ethical approval was obtained from the University Health Network and Sunnybrook Health Sciences Centre research ethics committees.

\section{Intervention}

Our wearable system consisted of 3 main components: Android Wear smartwatch, Android phone, and remote server. Participants were provided with instructions on the use and charging of the watch and the phone and how to fill out the symptom survey. The smartwatch collected sensor data that included audio from a microphone on the watch, heart rate, accelerometer, and gyroscope recordings. To avoid depleting the battery, the smartwatch recorded 2 out of every 10 minutes. This strategy resulted in an average battery life of 16 hours, which proved sufficient for a full day's use. The accelerometer and gyroscope were sampled at $20 \mathrm{~Hz}$. We used 2 smartwatch models: the LG Watch Urbane W150 (LG Electronics) and the Moto 360 2nd Generation (Motorola Mobility LLC; all $42 \mathrm{~mm}$ variations, including the sport and women's models), both running Android 6.0.1. The phone acted as a relay between the smartwatch and server and also prompted the user to fill out the symptom survey. We used LG Nexus 5 (LG Electronics; Android 6.0.1) or Moto G 3rd Generation (Motorola Mobility LLC; Android 6.0) phones. Each mobile phone is equipped with a 5 GB per month data plan, and our recording frequency and sampling rates were selected to fit within this limit. Phones were secured to prevent installation of other apps. The smartwatch sent sensor information to the mobile phone. These data were sent encrypted to a secure server, stored, and later made available for processing and analysis.

\section{Outcomes}

The primary outcome was whether patients with COPD were able to wear and maintain the smartwatches for 90 days. Secondary outcomes included the availability of heart rate, activity, and daily symptom surveys and qualitative feedback from participants at the end of the study. The heart rate and accelerometer data were collected directly from the smartwatches. Participants were also asked to complete a validated London COPD cohort daily symptom questionnaire consisting of 8 questions on the following symptoms: increased breathlessness, increased sputum color, increased sputum amount, a cold (such as runny or blocked nose), increased wheeze or chest tightness, sore throat, increased cough, and fever $[3,14]$. In accordance with the previous definitions, symptoms were classified as major (dyspnea, sputum purulence, and sputum volume) or minor (nasal discharge/congestion, wheeze, sore throat, cough, and fever). This survey has been validated to identify AECOPDs [3]. Patients who either dropped out or completed the study were also asked for their feedback on the wearable system, how they would want to interact with the system, and how the system could be improved. 


\section{Data Analysis}

User behavior was analyzed to determine whether the participants filled out the daily questionnaires on the mobile phone. Questionnaires were scored using the previously validated scoring process to determine the occurrences of AECOPDs [14]. To calculate the daily symptom score, each major symptom was weighted 5 points and minor symptoms were 1 point each. AECOPD was defined when the participant had a score greater than 5 for 2 consecutive days. Resolution of AECOPD occurred when the score was at 0 for 5 days.

Heart rate and accelerometer data were only considered if the device was not charging and their sensor status reading was reported as reliable. Audio data were collected and processed to detect coughing but will be described in another paper. We applied previously established methods to process raw accelerometer sensor data to determine sedentary behavior and physical activity [15]. Initially, raw data were converted to a motion summary count using an area under the curve calculation after removing the effects of gravity, which provided activity counts per minute. Thresholds for sedentary behavior $(<50.92$ counts per minute) and moderate-vigorous physical activity (>305.36 counts per minute) were used from a validation study

Figure 1. Enrollment and outcomes. of Android devices [16]. Python and the pandas, NumPy, and Scikit libraries were used for analysis.

Two authors (TS and RW) first independently analyzed participant feedback to look for common themes and then met and agreed upon common themes.

\section{Results}

\section{Patient Recruitment}

Out of 179 approached, 28 patients were recruited. People were primarily excluded for having a medical condition that impaired their ability to participate or being unable to speak English (Figure 1). The main reasons that eligible patients declined participation included privacy concerns and that they were uninterested in participating in a research study. Of the 28 enrolled patients, 16 completed the 90-day follow-up. The major reasons for dropping out of the study were that they were too sick (5 patients), they experienced technology issues (2), and they had privacy concerns (2). The baseline characteristics are shown in Table 1 . Of the 28 participants, the average age was 68.5 (range 41 to 84 ) years, and 10 participants were women. For the 16 participants who completed follow-up, the average age was 69.3 (range 52-84) years, and 4 were women.

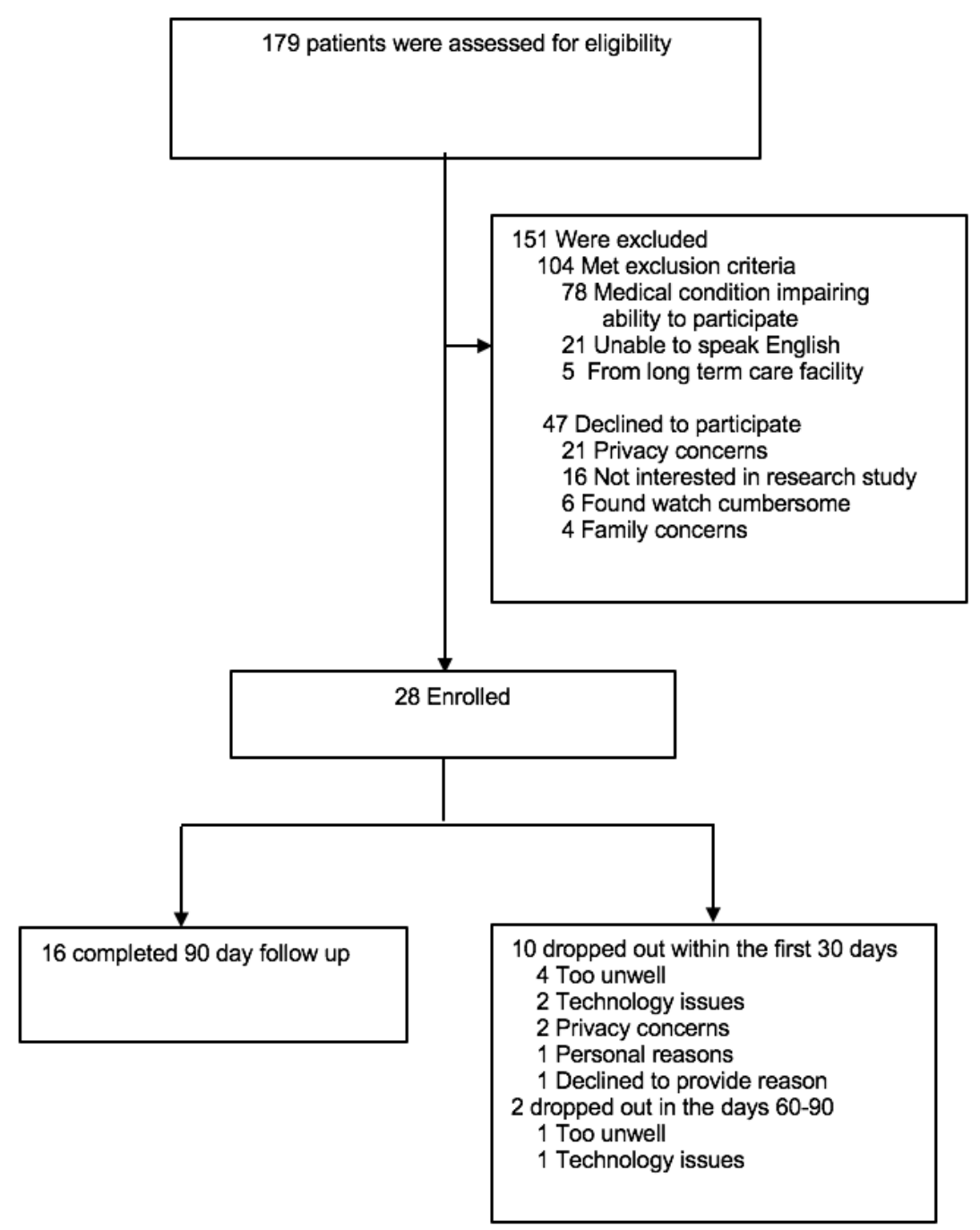


Table 1. Patient demographics.

\begin{tabular}{lll}
\hline Characteristics & All participants $(\mathrm{n}=28)$ & Participants who completed 90 days $(\mathrm{n}=16)$ \\
\hline Age, years, mean & 68.5 & 69.3 \\
Women, \% & 35 & 25 \\
$\mathrm{FEV}_{1}^{\mathrm{a}} / \mathrm{FVC}^{\mathrm{b}}, \%$ & 53 & 56 \\
$\mathrm{FEV}_{1}, \%$ & 57 & 63 \\
\hline
\end{tabular}

${ }^{\mathrm{a}} \mathrm{FEV}_{1}$ : forced expiratory volume in 1 second.

${ }^{\mathrm{b}} \mathrm{FVC}$ : forced vital capacity.

\section{Intervention}

There were several significant technical issues that occurred and were resolved in the initial 6 months. These issues prevented data to be uploaded and displayed errors on the watch. This caused 3 people to drop out as well as heart rate and accelerometer data to be unavailable for approximately 13 and 17 days, respectively. Other technical issues occurred intermittently in some smartwatches and mobile phones throughout the study period.

\section{Outcomes}

The daily survey questionnaires were completed an average of $47.5 \%$ of the time for all participants. For participants who completed the study, surveys were completed $71.7 \%$ of the time (range $21.1 \%$ to $100 \%$ ), and the scoring of these surveys indicated 24 exacerbations which lasted an average of 32 (SD $24)$ days. There was a large variation in how patients scored their symptoms; 6 of 16 patients were considered to be in exacerbation for more than $75 \%$ of the time monitored.

Patients had an average of 65.1 days of heart rate data available. For those days when data were available, there were on average 3170 heart rate recordings available per patient per day. Accelerometer data were available for 60.2 days on average. Due to the aforementioned technical issues, data were available for only 13 patients. For these patients, there were 592,000 accelerometer data points available per patient per day on average. After processing these to obtain sedentary behavior and moderate-to-vigorous physical activity, there were variations in patient activity (Table 2). An example of 1 patient's daily average heart rate, percentage of sedentary behavior and physical activity, and questionnaire responses is shown in Figure 2.

Table 2. Summary of survey, heart rate, and activity data by patient.

\begin{tabular}{|c|c|c|c|c|c|c|c|}
\hline \multirow[t]{2}{*}{ Patient number } & \multicolumn{2}{|l|}{ Survey } & \multicolumn{2}{|l|}{ Heart rate } & \multicolumn{3}{|l|}{ Activity } \\
\hline & Score, mean (SD) & Days completed & Mean (SD) & $\begin{array}{l}\text { Days of available } \\
\text { data }\end{array}$ & $\mathrm{MVPA}^{\mathrm{a}}$, mean $\%$ & $\begin{array}{l}\text { Sedentary behavior, } \\
\text { mean } \%\end{array}$ & $\begin{array}{l}\text { Days of available } \\
\text { data }\end{array}$ \\
\hline 1 & $1.4(2.7)$ & 90 & $79.7(8.7)$ & 51 & - & - & 0 \\
\hline 2 & $5.2(4.8)$ & 19 & $74.8(6.1)$ & 15 & - & - & 0 \\
\hline 3 & $6.5(4.8)$ & 90 & $84.8(5.4)$ & 12 & - & - & 0 \\
\hline 4 & $1.1(2.5)$ & 90 & $90.2(9.5)$ & 90 & 6.0 & 70.3 & 90 \\
\hline 5 & $7.1(5.4)$ & 89 & $72.6(7.8)$ & 90 & 8.6 & 67.3 & 90 \\
\hline 6 & $2.1(3.8)$ & 75 & $74.2(5.8)$ & 90 & 5.4 & 79.3 & 90 \\
\hline 7 & $4.3(4.0)$ & 79 & $79.4(10.7)$ & 90 & 2.4 & 76.1 & 89 \\
\hline 8 & $1.2(2.1)$ & 53 & 83.7 (16.5) & 71 & 11.1 & 60.9 & 69 \\
\hline 9 & $9.5(4.7)$ & 60 & $79.8(10.2)$ & 78 & 12.3 & 61.6 & 75 \\
\hline 10 & $3.0(4.3)$ & 59 & $78.2(11.3)$ & 62 & 4.6 & 62.5 & 61 \\
\hline 11 & $8.4(4.8)$ & 60 & $83.4(7.4)$ & 63 & 8.4 & 65.1 & 68 \\
\hline 12 & $3.1(3.7)$ & 90 & $80.4(6.4)$ & 90 & 13.3 & 64.2 & 90 \\
\hline 13 & $4.5(4.0)$ & 59 & $85.1(8.2)$ & 51 & 10.1 & 37.7 & 61 \\
\hline 14 & $11.5(4.8)$ & 90 & $85.0(5.7)$ & 90 & 13.0 & 56.9 & 90 \\
\hline 15 & $9.1(3.4)$ & 35 & $82.9(15.8)$ & 29 & 10.6 & 69.0 & 26 \\
\hline 16 & $7.1(5.3)$ & 62 & $78.6(4.0)$ & 64 & 18.9 & 52.7 & 64 \\
\hline All & $5.2(5.3)$ & 64.5 & $80.6(10.4)$ & 65.1 & 9.4 & 64.1 & 60.2 \\
\hline
\end{tabular}

${ }^{\mathrm{a}}$ MVPA: moderate to vigorous physical activity. 
Figure 2. A participant's heart rate, activity, and symptom scores over 90 days.

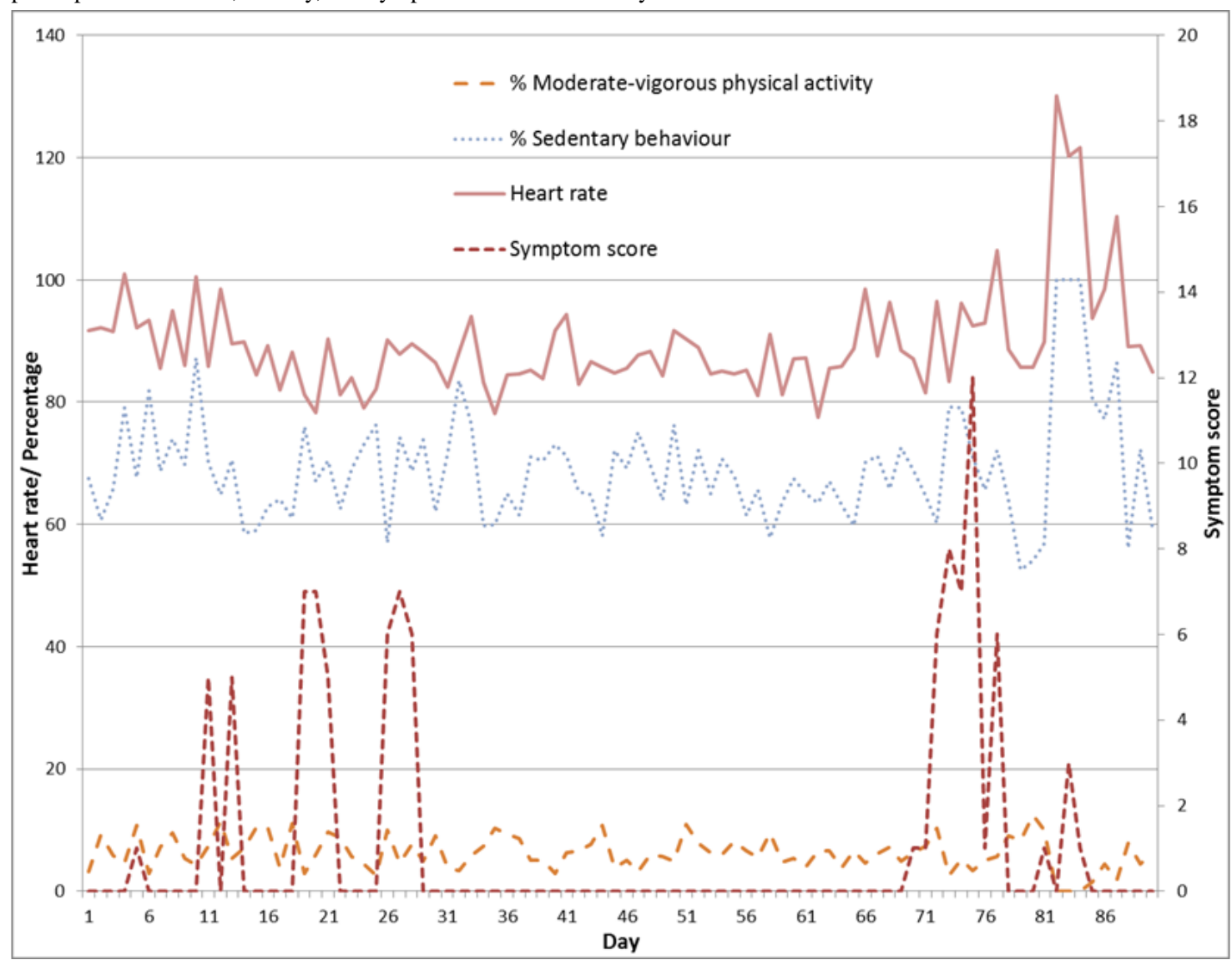

Fifteen participants provided feedback on issues concerning using a COPD wearable and what would make them regularly use a COPD wearable. Those who dropped out expressed privacy issues with the study specifically recording audio and others noted technology issues with the smartwatch system that made them want to stop participating. There were concerns with the bulky smartwatch, and some expressed desire for a thinner, lighter, and more stylish wristband.

Participants expressed that they wanted an app and a device that could provide more feedback. This feedback would include information about themselves in terms of their heart rate, coughing data, and oxygen saturation. Participants were also interested in gaining knowledge by accessing COPD educational material, breathing exercises, and physical activity exercises. Some participants also liked the idea of their health care provider being alerted if their symptoms were getting worse while others worried their health care provider would find it a nuisance.

\section{Discussion}

\section{Principal Findings}

We conducted a feasibility study of smartwatches in people with COPD and found that they will wear and maintain smartwatches that passively monitor audio, heart rate, and physical activity data almost continuously. Thus, smartwatches appear to be a viable platform for the intensive sensor data collection that may be required to detect AECOPDs early.

The frequency of sensor data collected was much greater than the frequency of other previously described interventions, as we collected data for 2 minutes out of every 10 minutes. While most previous COPD telemonitoring studies collected data daily [10], the one study with more frequent collection used a custom wristband that was designed to perform 5 measurements of their oxygen saturation, heart rate, body temperature, and physical activity every 3 hours [17]. However, they obtained on average only 4 recordings per patient day, and data were available for only $60 \%$ of patient days, seemingly due to lack of use of their system.

We found that there were a high percentage of patients who were not interested in participating. While telemonitoring studies have not consistently reported their recruitment rate $[18,19]$, our recruitment rate was lower than the rate found in the custom COPD wristband study (16\% vs 57\%) and our dropout rate was higher ( $43 \%$ vs $22 \%$ ) [17]. This may have been due to privacy concerns of recording audio or the differences in recruitment settings, as one of our sources of patients was hospitalized patients who were often too sick to participate. We heard from participants that to increase enrollment, we should provide patients with feedback about their activity, their heart rate, and how to better manage their COPD because they did not just want a passive monitoring device.

We found that we can collect symptom data through the daily symptom card, but this was not consistently completed even in our motivated participants. The availability of symptoms surveys that our patients provided was similar to the literature $(70 \%$ in our study vs $77 \%$ in a similar study) [20]. This may support the approach for data collection through passive sensors because it 
may be problematic to reliably obtain symptom surveys from patients with COPD on a long-term basis [13].

We found gender differences in recruitment with more men agreeing to participate and more men completing the study. This may be due to the large size of the smartwatches as several people commented on the bulkiness of the smartwatches. These gender differences should be explored further to determine if there are other factors which may deter women from using a wearable to help manage their COPD.

\section{Limitations}

There were significant limitations to our study. Many patients approached were not interested in participating. While this may partially be due to being part of a research study, it does call into question the generalizability of our results. We also had significant technical issues that negatively affected the retention of users and availability of data. Specifically, we found that the Android Wear platform was not a stable platform due to constant updates and operating system changes. Unfortunately, we were unable to definitively determine how much physiologic data were unavailable due to technical issues as opposed to not charging the device. As well, while the daily symptom score has been previously correlated with AECOPDs, we found a large variation in how patients would report symptoms. Some reported symptoms that were above their baseline, but some appeared to report any symptoms despite instruction. While the daily diary cards have been validated on paper [14], their use on a mobile phone app should be validated prior to further use. Finally, we collected heart rate and activity data but their accuracy is unclear because the smartwatches did not contain medical grade sensors.

Now that we have confirmed that some patients with COPD will use wearable devices that can obtain physiologic data, our next step is to engage patients in further depth to determine what they would like to see in a wearable device to help manage their COPD. This should increase the uptake and retention of both men and women with COPD. Further work would also include the validation of physiologic signals including cough detection, heart rate, and physical activity in predicting early AECOPDs.

\section{Conclusion}

We found that patients with COPD will wear and maintain smartwatches that passively monitor audio, heart rate, and physical activity, and we were able to reliably capture near-continuous patient data. Further work is necessary to increase acceptability and improve the patient experience.

\section{Acknowledgments}

This study was supported by the Innovation Fund of the Alternative Funding Plan for the Academic Health Sciences Centres of Ontario. This work was also supported by Aging Gracefully across Environments using Technology to Support Wellness, Engagement and Long Life-Networks of Centres of Excellence (AGE-WELL NCE Inc), a national research network supporting research, networking, commercialization, knowledge mobilization, and capacity-building activities in technology and aging to improve the quality of lives of Canadians and contribute to the economic impact of Canada. AGE-WELL is a member of the NCE, a Government of Canada program that funds partnerships between universities, industry, government, and not-for-profit organizations. RW is supported by an award from the Mak Pak Chiu and Mak-Soo Lai Hing Chair in General Internal Medicine, University of Toronto.

\section{Conflicts of Interest}

None declared.

\section{References}

1. World Health Organization. 2017. Chronic obstructive pulmonary disease fact sheet URL: http://www.who.int/mediacentre/ factsheets/fs315/en/[WebCite Cache ID 6ySdbVWVB]

2. OHTAC COPD Collaborative. Chronic obstructive pulmonary disease (COPD) evidentiary framework. Ont Health Technol Assess Ser 2012;12(2):1-97 [FREE Full text] [Medline: 23074430]

3. Aaron SD, Donaldson GC, Whitmore GA, Hurst JR, Ramsay T, Wedzicha JA. Time course and pattern of COPD exacerbation onset. Thorax 2012 Mar;67(3):238-243. [doi: 10.1136/thoraxjnl-2011-200768] [Medline: 22008189]

4. Global Initiative for Chronic Obstructive Lung Disease. 2016. Global strategy for the diagnosis, management and prevention of chronic obstructive pulmonary disease URL: http://goldcopd.org/download/120/[WebCite Cache ID 6zQ7QCOLE]

5. Spencer S, Calverley PMA, Burge PS, Jones PW. Impact of preventing exacerbations on deterioration of health status in COPD. Eur Respir J 2004 May;23(5):698-702 [FREE Full text] [Medline: 15176682]

6. Kessler R, Ståhl E, Vogelmeier C, Haughney J, Trudeau E, Löfdahl C, et al. Patient understanding, detection, and experience of COPD exacerbations: an observational, interview-based study. Chest 2006 Jul;130(1):133-142. [doi: 10.1378/chest.130.1.133] [Medline: 16840393]

7. Donaldson GC, Seemungal TAR, Bhowmik A, Wedzicha JA. Relationship between exacerbation frequency and lung function decline in chronic obstructive pulmonary disease. Thorax 2002 Oct;57(10):847-852 [FREE Full text] [Medline: 12324669] 
8. Kanner RE, Anthonisen NR, Connett JE, Lung Health Study Research Group. Lower respiratory illnesses promote FEV(1) decline in current smokers but not ex-smokers with mild chronic obstructive pulmonary disease: results from the lung health study. Am J Respir Crit Care Med 2001 Aug 01;164(3):358-364. [doi: 10.1164/ajrccm.164.3.2010017] [Medline: 11500333]

9. Wilkinson TMA, Donaldson GC, Hurst JR, Seemungal TAR, Wedzicha JA. Early therapy improves outcomes of exacerbations of chronic obstructive pulmonary disease. Am J Respir Crit Care Med 2004 Jun 15;169(12):1298-1303. [doi:

10.1164/rccm.200310-14430C] [Medline: 14990395]

10. Sanchez-Morillo D, Fernandez-Granero MA, Leon-Jimenez A. Use of predictive algorithms in-home monitoring of chronic obstructive pulmonary disease and asthma: a systematic review. Chron Respir Dis 2016 Aug;13(3):264-283. [doi: 10.1177/1479972316642365] [Medline: 27097638]

11. Cimperman M, Brenčič MM, Trkman P, Stanonik MDL. Older adults' perceptions of home telehealth services. Telemed J E Health 2013 Oct;19(10):786-790 [FREE Full text] [doi: 10.1089/tmj.2012.0272] [Medline: 23931702]

12. Subramanian U, Hopp F, Lowery J, Woodbridge P, Smith D. Research in home-care telemedicine: challenges in patient recruitment. Telemed J E Health 2004;10(2):155-161. [Medline: 15319045]

13. Sanders C, Rogers A, Bowen R, Bower P, Hirani S, Cartwright M, et al. Exploring barriers to participation and adoption of telehealth and telecare within the Whole System Demonstrator trial: a qualitative study. BMC Health Serv Res 2012;12:1-12 [FREE Full text] [doi: 10.1186/1472-6963-12-220] [Medline: 22834978]

14. Seemungal TA, Donaldson GC, Bhowmik A, Jeffries DJ, Wedzicha JA. Time course and recovery of exacerbations in patients with chronic obstructive pulmonary disease. Am J Respir Crit Care Med 2000 May;161(5):1608-1613. [doi: 10.1164/ajrccm.161.5.9908022] [Medline: 10806163]

15. Rosenberger ME, Haskell WL, Albinali F, Mota S, Nawyn J, Intille S. Estimating activity and sedentary behavior from an accelerometer on the hip or wrist. Med Sci Sports Exerc 2013 May;45(5):964-975 [FREE Full text] [doi: 10.1249/MSS.0b013e31827f0d9c] [Medline: 23247702]

16. Hekler EB, Buman MP, Grieco L, Rosenberger M, Winter SJ, Haskell W, et al. Validation of physical activity tracking via Android smartphones compared to ActiGraph accelerometer: laboratory-based and free-living validation studies. JMIR Mhealth Uhealth 2015 Apr 15;3(2):e36 [FREE Full text] [doi: 10.2196/mhealth.3505] [Medline: 25881662]

17. Pedone C, Chiurco D, Scarlata S, Incalzi RA. Efficacy of multiparametric telemonitoring on respiratory outcomes in elderly people with COPD: a randomized controlled trial. BMC Health Serv Res 2013 Mar 06;13:82 [FREE Full text] [doi: 10.1186/1472-6963-13-82] [Medline: 23497109]

18. Bellos CC, Papadopoulos A, Rosso R, Fotiadis DI. Identification of COPD patients' health status using an intelligent system in the CHRONIOUS wearable platform. IEEE J Biomed Health Inform 2014 May;18(3):731-738. [doi: 10.1109/JBHI.2013.2293172] [Medline: 24808219]

19. Colantonio S, Govoni L, Dellacà RL, Martinelli M, Salvetti O, Vitacca M. Decision making concepts for the remote, personalized evaluation of COPD patients' health status. Methods Inf Med 2015;54(3):240-247. [doi: 10.3414/ME13-02-0038] [Medline: 25502493]

20. Sund ZM, Powell T, Greenwood R, Jarad NA. Remote daily real-time monitoring in patients with COPD: a feasibility study using a novel device. Respir Med 2009 Sep;103(9):1320-1328 [FREE Full text] [doi: 10.1016/j.rmed.2009.03.017] [Medline: 19375294]

\section{Abbreviations}

AECOPD: acute exacerbation of chronic obstructive pulmonary disease

AGE-WELL NCE: Aging Gracefully across Environments using Technology to Support Wellness, Engagement and Long Life-Networks of Centres of Excellence

COPD: chronic obstructive pulmonary disease

MVPA: moderate to vigorous physical activity

Edited by G Eysenbach; submitted 16.02.18; peer-reviewed by D Morillo, M Fernandez-Granero; comments to author 29.03.18;
revised version received 20.04.18; accepted 26.04.18; published 14.06.18
Please cite as:
Wu R, Liaqat D, de Lara E, Son T, Rudzicz F, Alshaer H, Abed-Esfahani P, Gershon AS
Feasibility of Using a Smartwatch to Intensively Monitor Patients With Chronic Obstructive Pulmonary Disease: Prospective Cohort
Study
JMIR Mhealth Uhealth 2018;6(6):e10046
URL: $\underline{\text { http://mhealth.jmir.org/2018/6/e10046/ }}$
doi: $\underline{10.2196 / 10046}$
PMID: $\underline{29903700}$


CRobert Wu, Daniyal Liaqat, Eyal de Lara, Tatiana Son, Frank Rudzicz, Hisham Alshaer, Pegah Abed-Esfahani, Andrea S Gershon. Originally published in JMIR Mhealth and Uhealth (http://mhealth.jmir.org), 14.06.2018. This is an open-access article distributed under the terms of the Creative Commons Attribution License (https://creativecommons.org/licenses/by/4.0/), which permits unrestricted use, distribution, and reproduction in any medium, provided the original work, first published in JMIR mhealth and uhealth, is properly cited. The complete bibliographic information, a link to the original publication on http://mhealth.jmir.org/, as well as this copyright and license information must be included. 